\title{
Factory Downtime Minimization through Tracking of Maintenance Information System of Metahara Sugar Factory, Ethiopia
}

\author{
Minale Getachew \\ Research and Training, Sugar Technology Research Directorate, Ethiopian Sugar Corporation, \\ Post Box No: 15, Ethiopia
}

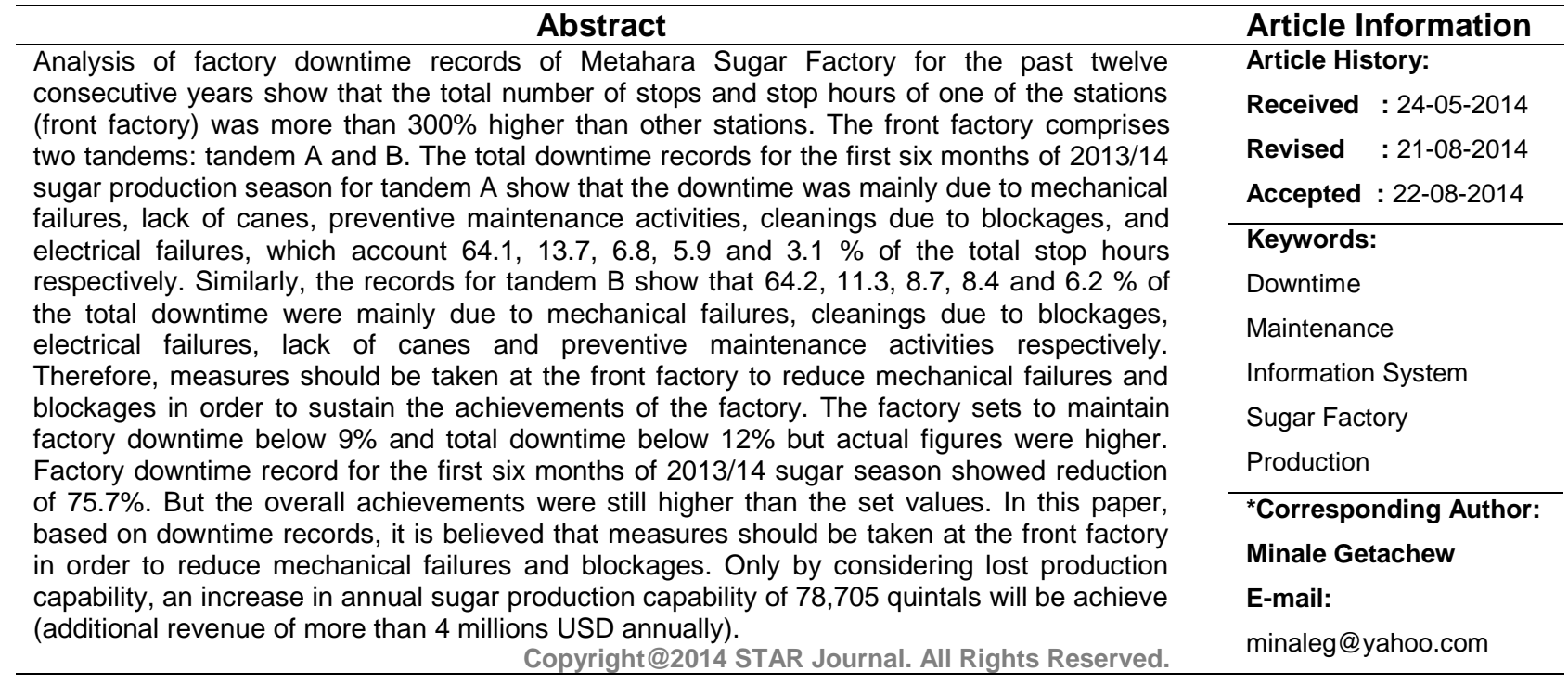

\section{INTRODUCTION}

Ethiopian sugar industries mainly process sugar from sugarcane and ethanol from molasses, which is one of the by-products of sugar processing. Metahara Sugar Factory is one of them and located at $200 \mathrm{~km}$, east of the capital, Addis Ababa in Oromia region with annual production capacity of 1.3 million quintal of sugar and 12.5 million liter of ethanol. The factory has two tandems with total crushing capacity of about 5,300 tonnes of cane per day. Tandem A has a capacity of 1770 tonnes of cane per day and tandem B with 3600 tonnes of cane per day according to Metahara Sugar Factory (2013/14).

One of the main factor affecting sugar production capacity and competitiveness is factory downtime. Equipment downtime which includes not only material and labor cost to get back the equipment to operating condition, but also it includes costs resulting from lost production capability; moreover, performance decrease due to by-pass operations and decreased worker productivity (Piper, 2005). Due to factory downtime Metahara Sugar Factory lost production capability of about 221 quintals of sugar per hour based on the current crushing capacity of the factory.
Production efficiency can often be greatly improved by identifying the reasons and extent of production stoppages. Application software known as Maintenance Information System developed by Omni Tech Pvt. Ltd. Co. Software Center, Addis Ababa, Ethiopia is used by the factory since 2000 for tracking downtime, which means downtime data acquisition, reporting and analysis for optimization of uptime and output.

Implementing a downtime tracking system helps to identify the real causes for lost production and increase output. Options to improve system reliability and to reduce equipment downtime, emergency maintenance requirements and total maintenance costs can also be achieved by analyzing recorded downtimes (Piper, 2005).

Preventive maintenance activities are planned activities carried out to minimize failure of equipment but corrective maintenance activities, which are unplanned and suddenly occurring maintenance activities, are performed when the equipment fail. The factory has an annual factory overhaul program to bring the equipment up to A-level condition before preventive maintenance could be effective (Kjell, 2001). 


\section{Minale Getachew}

The minimum period of time required to conduct downtime analysis is at least six months in order to avoid artificial skewing of data due to failure of single piece of equipment. More accurate results will be obtained if it is performed on yearly basis (Piper, 2005).

\section{MATERIALS AND METHODS}

The factory records downtime and related information such as causes, failure types and stop hours. The information is stored manually at the Maintenance Information System software developed exclusively for the factory. This database is used as chief source of information to carry out analysis.

Analysis of downtime per tandem per stations was carried out by considering records of both preventive and corrective maintenances activities stored for the past consecutive twelve sugar seasons to identify a station stopped for large number of hours.
Sci. Technol. Arts Res. J., July-Sep 2014, 3(3): 142-146

Analysis of downtime per tandem per failure types on the station stopped for large number of hours was carried out by considering only records of corrective maintenances activities stored for the first six months of $2013 / 14$ sugar season to identify the main failure types causing the downtime.

Records of factory downtime level for the first six months of 2013/14 sugar season were used to evaluate lost production capabilities of the factory.

\section{RESULTS AND DISCUSSION}

Analysis of Downtime per Tandem per Stations

Analysis results of the factory downtime records for the past twelve consecutive years are shown in Figures 1, 2, 3 and 4.

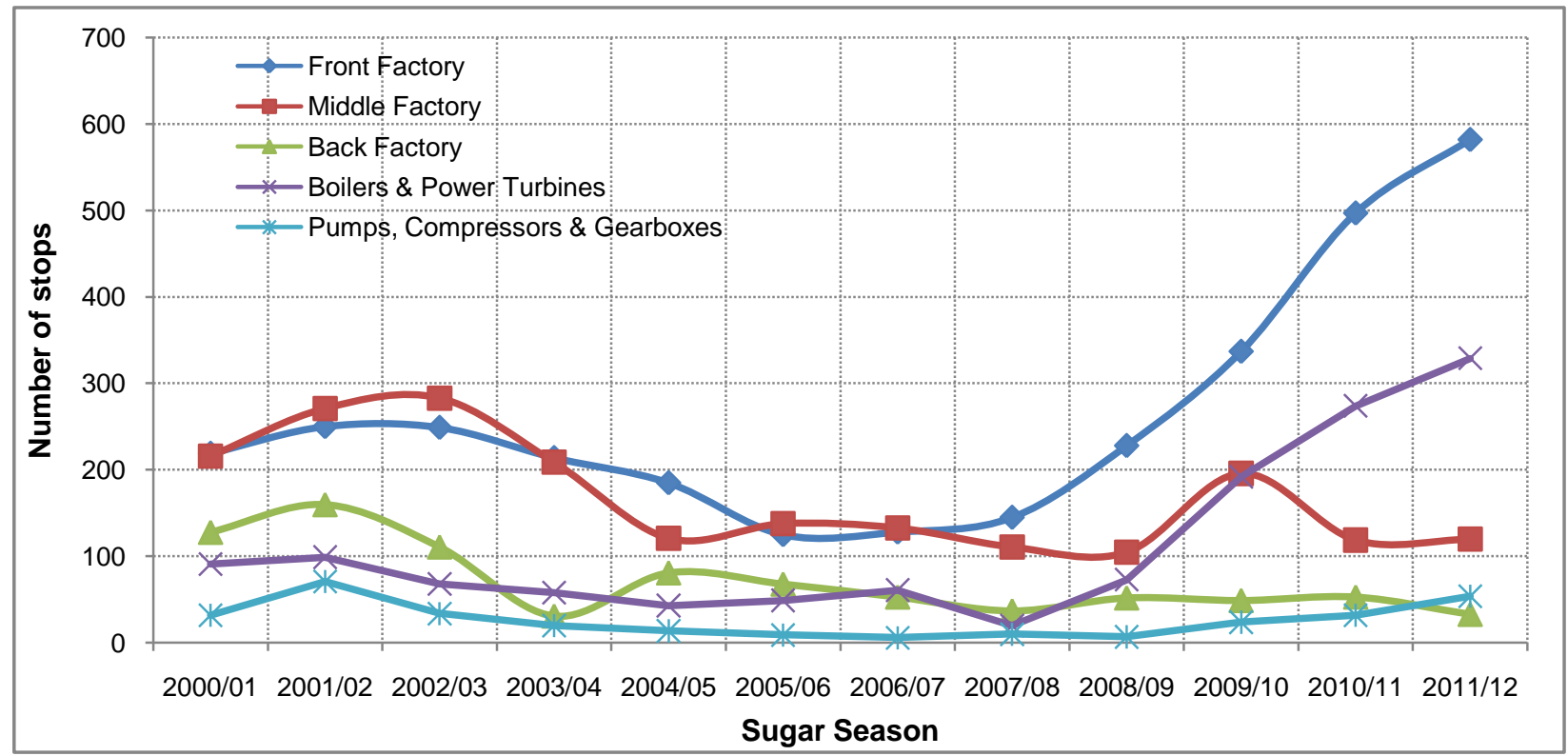

Figure 1: Number of stops of tandem A due to failures occurred at different stations

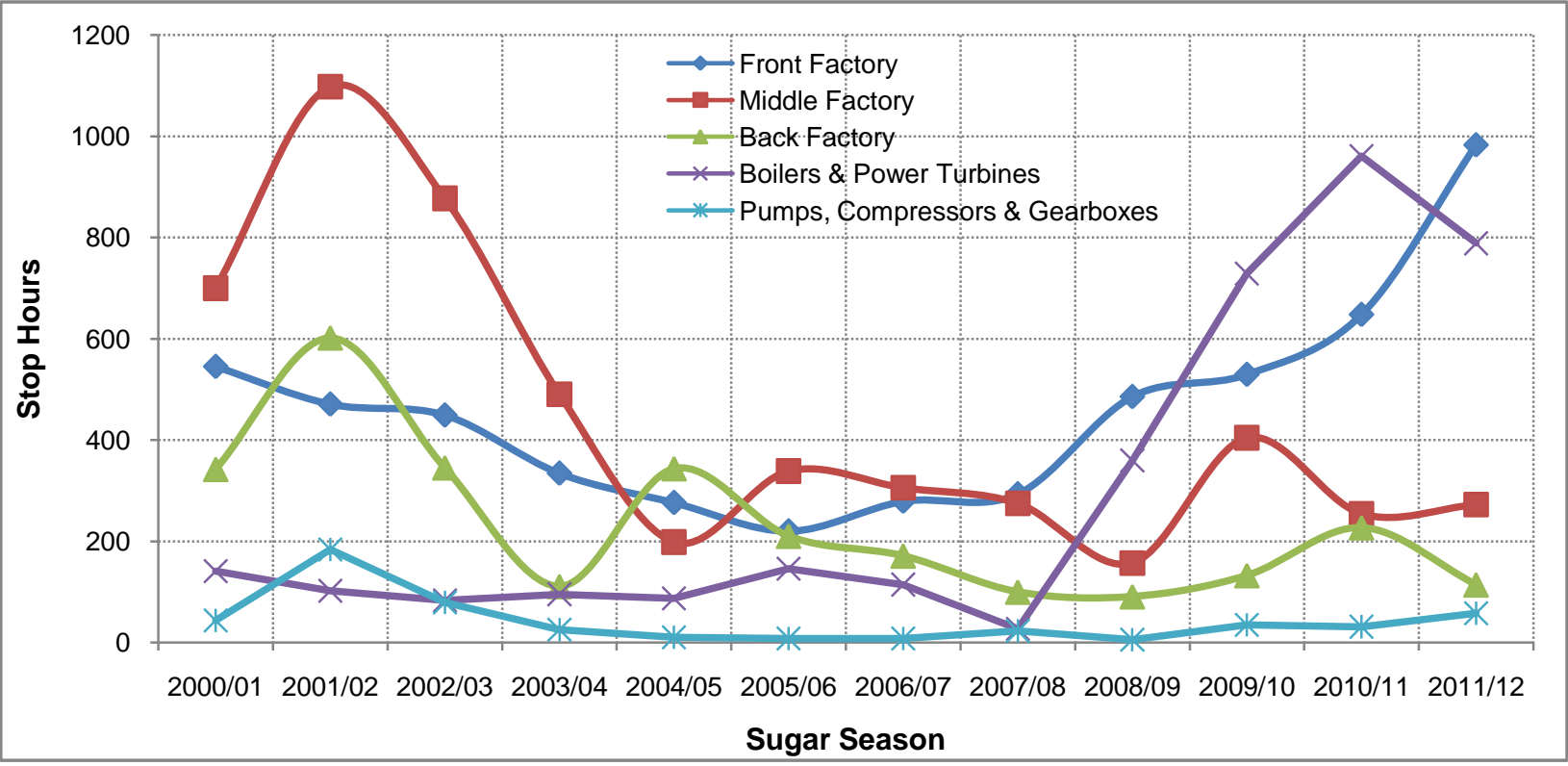

Figure 2: Stop hours of tandem A due to failures occurred at different stations 


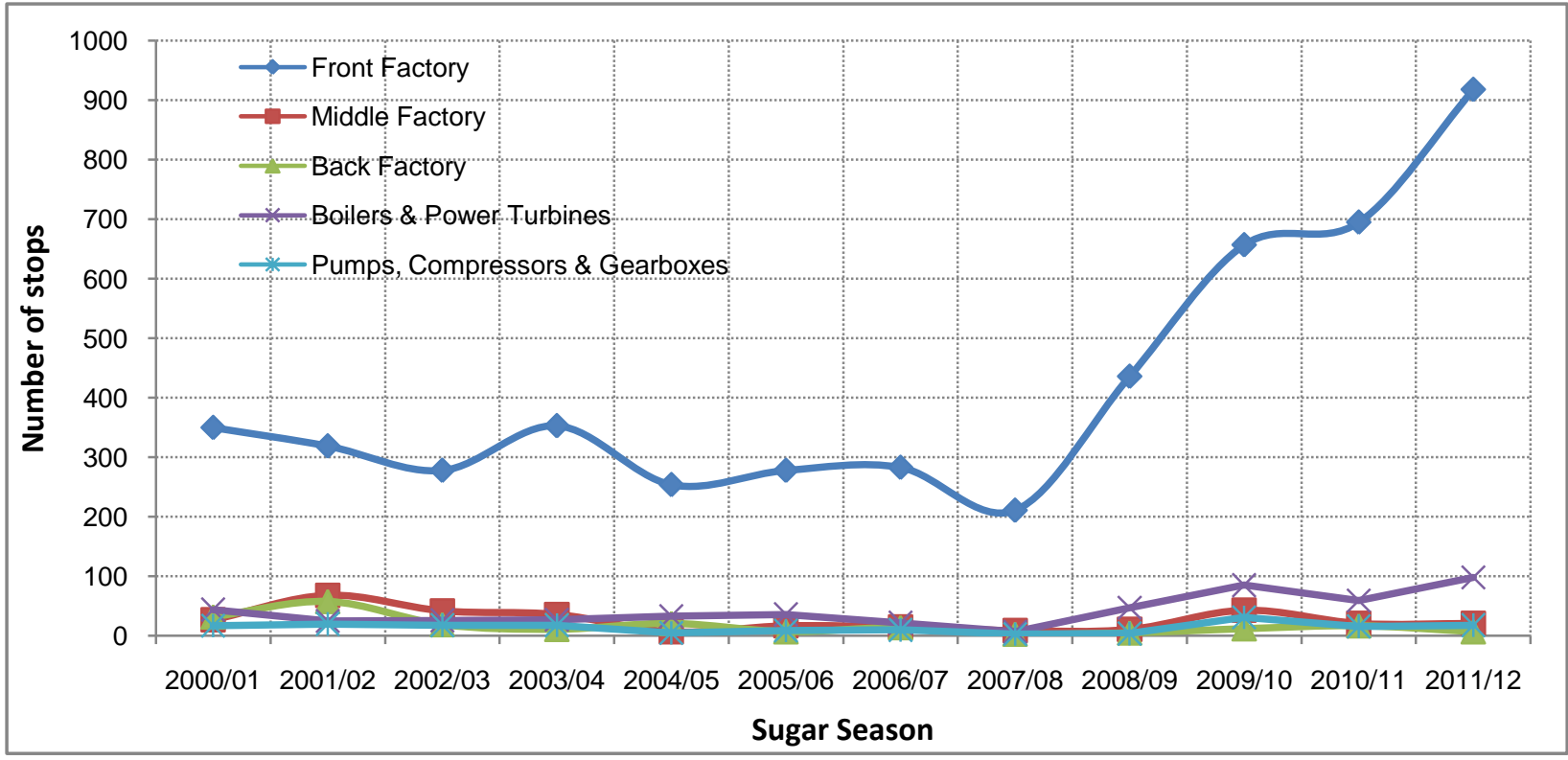

Figure 3: Number of stops of tandem B due to failures occurred at different stations

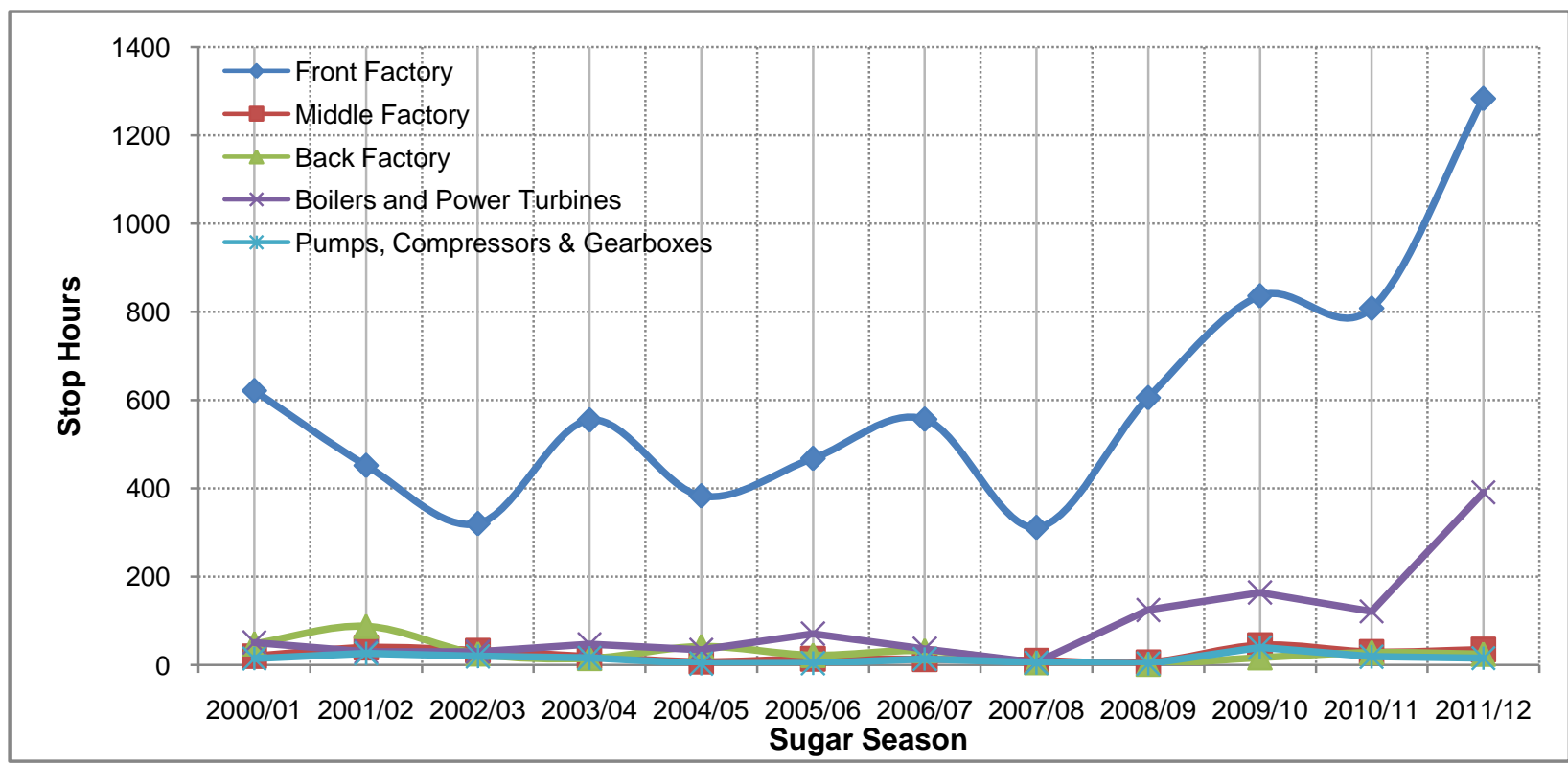

Figure 4: Stop hours of tandem B due to failures occurred at different stations

Figures 1 and 2 shows the number of stops and stop hours of tandem A respectively due to failures occurred at five stations of the factory: front factory, middle factory, back factory, boilers and power turbines station, and pumps, compressors and gearboxes station. Stoppage of production at tandem $A$ is mainly due to failures occurred at the front factory and boilers and power turbines station. These two stations have decreasing trend of number of stops and stop hours until 2007/08 sugar season but after that they have shown sharply increasing trend. Before 2004/05 sugar season the number of stops and stop hours of tandem $A$ due to failure at middle factory was relatively higher but since then it attained steady pattern. Currently, the factory carried out rehabilitation program on most frequently failing boiler during overhaul program and sugar production season so that root cause of most failures occurred at boilers and power turbines station was recitfied. Therefore, failures occurred at the front factory caused large number of stops for tandem $A$.
Figures 3 and 4 show number of stops and stop hours of tandem $B$ respectively due to failures occurred at the five stations. Similar to tandem A, failures occurred at the front factory caused large number of stops for tandem B. The overall trend of number of stops and stop hours of tandem $B$ due to failures at the front factory have identical trend, i.e., a decreasing trend until 2007/08 sugar season but after that it has a sharply increasing trend.

For both tandems the front factory has caused large number of stops with high stop hours. So, performing downtime analysis per failure types on the front factory is crucial in order to minimize the downtime.

\section{Analysis of Downtime per Tandem per Failure Types}

Figures 5 and 6 show stop hours caused by failure types in percent based on the records of the first six months of 2013/14 sugar season. Mechanical failures alone accounts for about $64.2 \%$ of the downtime and blockages account for about $9.9 \%$. 


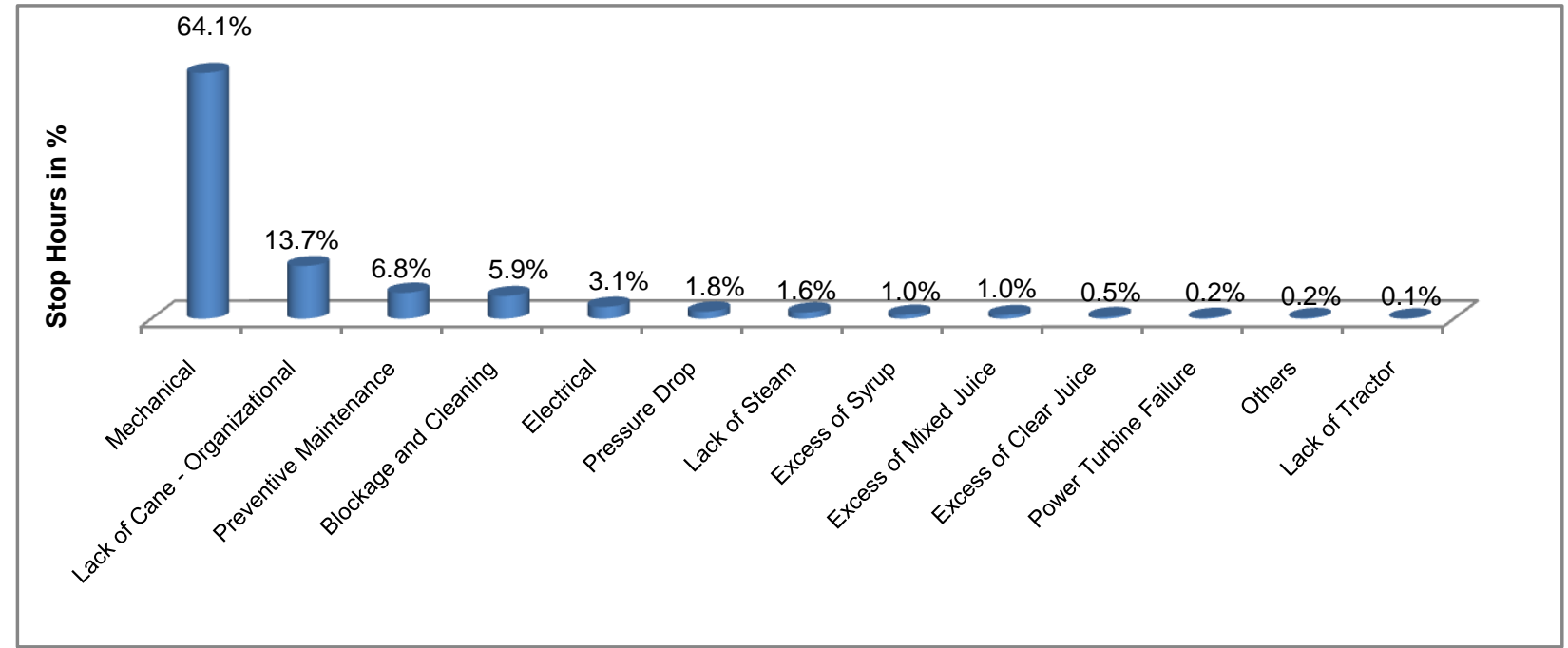

Figure 5: Stop hours per failure types for tandem A for the first six months of 2013/14 sugar season

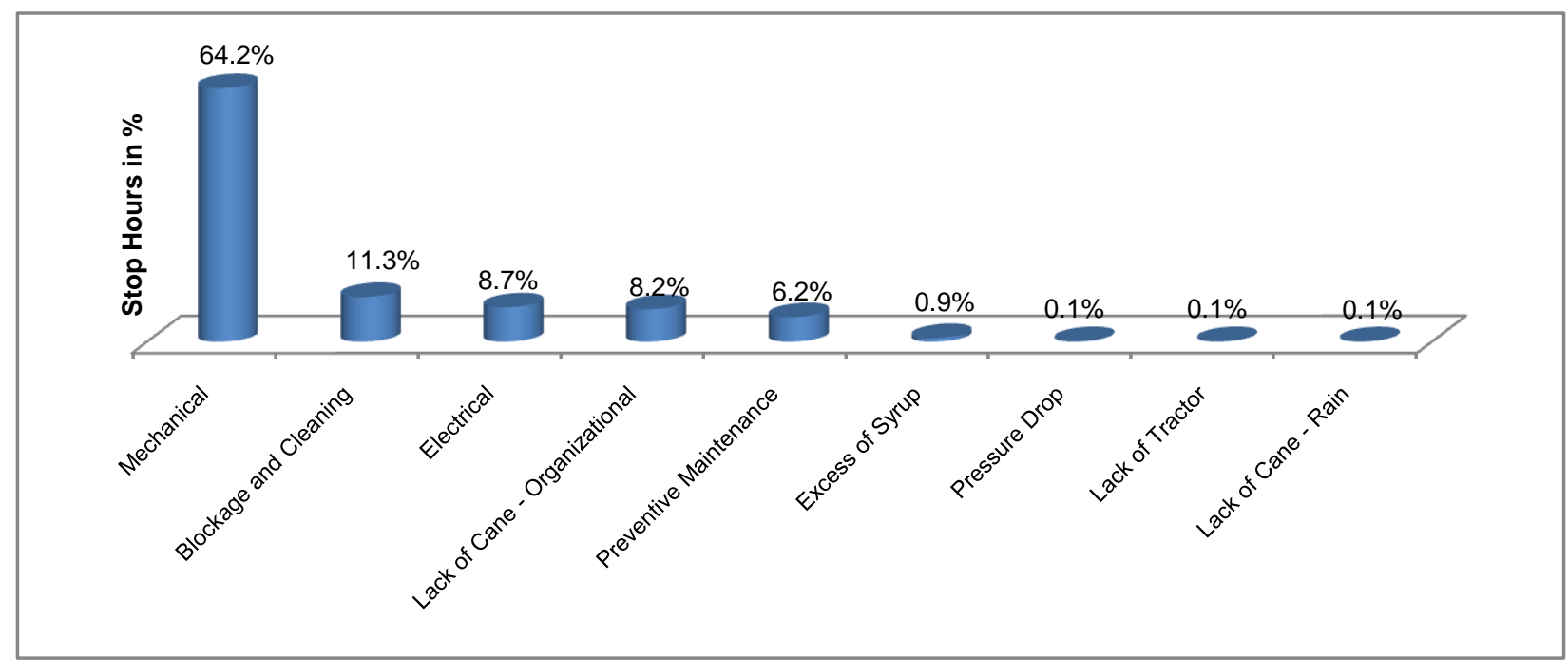

Figure 6: Stop hours per failure types for tandem B for the first six months of 2013/14 sugar season

\section{Analysis of Factory Downtime}

The factory achieved a minimum factory downtime of about $6.63 \%$ during $2007 / 08$ sugar season. But the set value of $2013 / 14$ sugar season, which is $9 \%$, is used as a bench mark to evaluate lost production capabilities of the factory.
Factory downtime records of the factory for the first six months of 2013/14 sugar season are shown in Figure 7. Maximum factory downtime of $29.09 \%$ was achieved on November, 2013 as "expected" and minimum factory downtime of $7.07 \%$ was achieved on April, 2014.

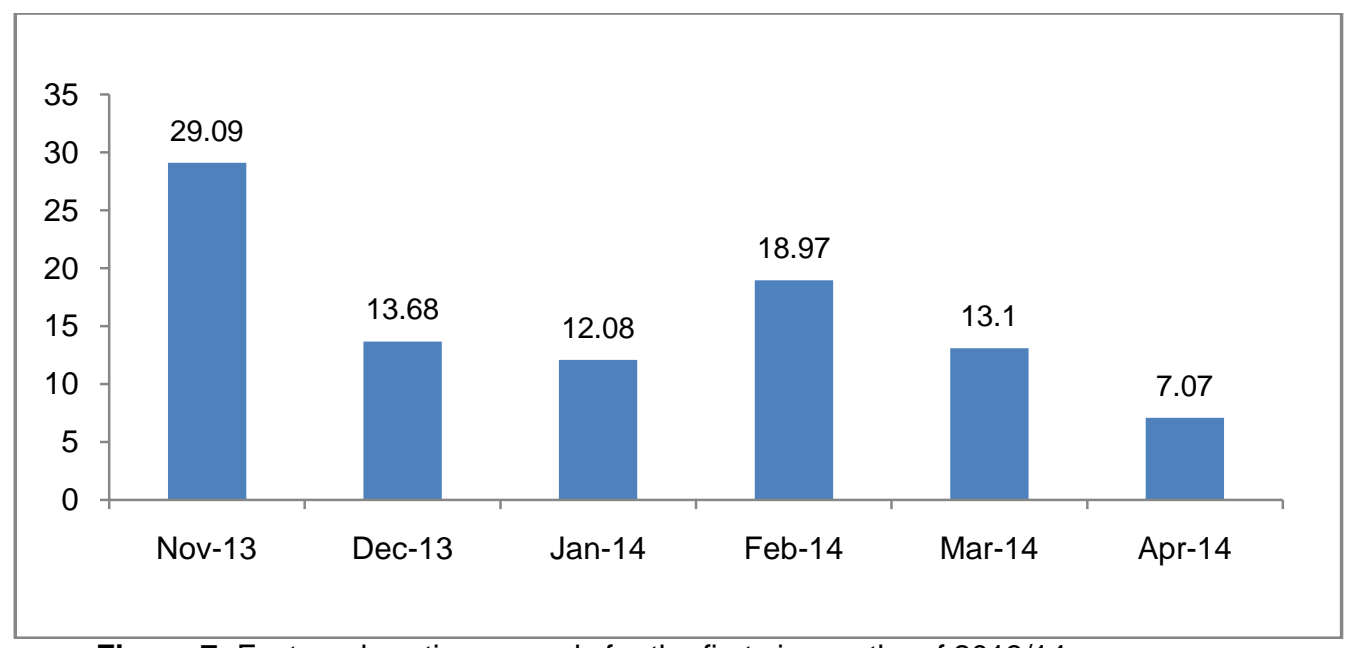

Figure 7: Factory downtime records for the first six months of 2013/14 sugar season 


\section{Minale Getachew}

The factory has an approximate average monthly downtime of $14.5 \%$, which is $5.5 \%$ greater than the bench marked value. Based on the factory cane crushing capacity, it has a potential of increasing current sugar production by 8,745 quintals per month. The factory plan to operate for about nine months during this sugar season so there will be a potential of 78,705 quintals per annum.

\section{CONCLUSIONS}

To achieve the set value of downtime the mechanical failures and blockages at the front factory should be rectified. Close investigation of downtime records revealed that most of the mechanical failures occurred at sugarcane mills, which are found within the front factory, and also blockage occurred during feeding of prepared cane to the mills for juice extraction. Research findings on sugar technology clearly emphasize the fact that for the success of sugar factories focusing on defect elimination rather than improving maintenance practice is essential and makes them competent (Letizia and Brown, 2010). Therefore, emphasis should be given on defect elimination rather than improving maintenance practice in order to avoid the root causes of most of the mechanical failures and blockages. Not only research findings but also increasing trends of price of spare parts favor the concept of defect elimination.

Replacing the existing mills by the state of the art technology is capital intensive but upgrading them by replacing inefficient components are not only low cost alternative, but also very important in minimization of most drawbacks of the existing mills. In sight of this, proven technologies easy to implement and integrate with negligible maintenance were preferred in order to realize the targeted downtime with minimum investment. Thus, replacing inefficient tail bar coupling assembly (Tosio, 2010) of the mill with rope coupling, which is completely
Sci. Technol. Arts Res. J., July-Sep 2014, 3(3): 142-146

replaced the tail bar coupling assembly (Mane and Murugkar, 2003), and up grading automatic cane feeding system to receive signal based on load on primary mill load should be implemented in order eliminate most of mechanical failures and blockages. The recommended technologies are economically feasible with a payback period of less than two months since most of the parts can be manufactured locally. Moreover, replacing steam turbines, which are used to drive the mills, by electric motors, reduce operational and maintenance cost of the front factory.

\section{REFERENCES}

Metahara Sugar Factory (2013/14). Operating Budget of Metahara Sugar Factory.

Piper E. James. (2005). Operations and Maintenance Manual for Energy Management. Standard Publishers Distributors, India. pp 318-330.

Kjell B. Zandin (2001). Maynard's Industrial Engineering Handbook, $5^{\text {th }}$ ed. Mc Graw-Hill Companies, New York. pp 16.29-16.43.

Letizia, I. and Brown, R. (2010). Factory Reliability Improvement through Downtime Monitoring and Defect Elimination. Proceedings of the Australian Society of Sugar Cane Technology 32: 646-654.

Mane, C.G. and Murugkar, V.M. (2003). Rope Coupling for Sugarcane Drives. Proceedings of the $65^{\text {th }}$ Annual Convention of the Sugar Technologies' Association of India, August 22-24, 2003: E21-E29.

Peter Rein (2007). Cane Sugar Engineering. Verlas Dr. Albert Bartens KG, Berlin. pp 123-125.

Tosio, C.T. (2010). Sugar-mill Coupling Development since 1987. Proceedings of the Australian Society of Sugar Cane Technology 27:1-8. 